\title{
Influence of knowledge of peak flow on self assessment of asthma: studies with a coded peak flow meter
}

\author{
C M B HIGGS, R B RICHARDSON, D A LEA, G T R LEWIS, G LASZLO \\ From the Respiratory Department, Bristol Royal Infirmary, Bristol, and the Department of Electrical \\ Engineering, Polytechnic of Wales, Pontypridd, South Glamorgan
}

ABSTRACT A portable peak flow meter based on a turbine transducer that can display results in code has been developed. Its performance compares well with the Wright peak flow meter. Records of subjective self assessment of asthma on a visual analogue scale and of peak flow (PEF) were compared in 12 subjects with asthma. PEF measurements were made with a coded meter for two weeks and an uncoded meter for two weeks in random order. The correlation between visual analogue scale score and PEF was invariably stronger when PEF was known. Changes in perception of asthma were measured by comparing the slopes and relative positions of the regressions of visual analogue on PEF. When PEF was uncoded awareness of asthma was significantly increased in five patients, predominantly those whose perception was poorest while they were using the coded meter, and decreased in only one patient. In two patients the results were unsuitable for this type of analysis. Knowledge of PEF therefore may influence subjective self assessment in patients with bronchial asthma. For objective studies of symptoms of asthma, PEF readings should be unknown to the patient. Perception of asthma may, however, be improved in patients with poor ability to detect changes in bronchial calibre by uncoded measurement of peak flow at home.

In the outpatient investigation of asthma it is customary to give patients a peak flow meter and a diary card to record their peak expiratory flow (PEF) together with some index of symptoms. The relationship between the subjective self assessment and the objective PEF measurement provides information about perception of asthma. The peak flow meters in common use are the Wright peak flow meter and the mini Wright peak flow meter, with which the patient records the PEF from the dial or scale. It is possible that the knowledge of PEF measurements thus gained influences subjective self assessment and alters perception of asthma.

We have developed a portable peak flow meter with an electronic display that can be coded. We compared our instrument with the Wright peak flow meter and investigated whether self assessment of asthma is influenced by knowledge of recent PEF measurements.

Address for reprint requests: Dr CMB Higgs, Royal United Hospital, Bath BAI 3NG.

Accepted 19 March 1986

\section{The coded peak flow meter}

The coded peak flow meter (the Codaflow) consists of a turbine flow transducer, with ancillary electronics and digital display ${ }^{1}$ (fig 1). Airflow through the turbine rotates a low inertia vane, which sets up an electrical impulse as it passes a metal plate. The pulses are preamplified within the transducer handle and

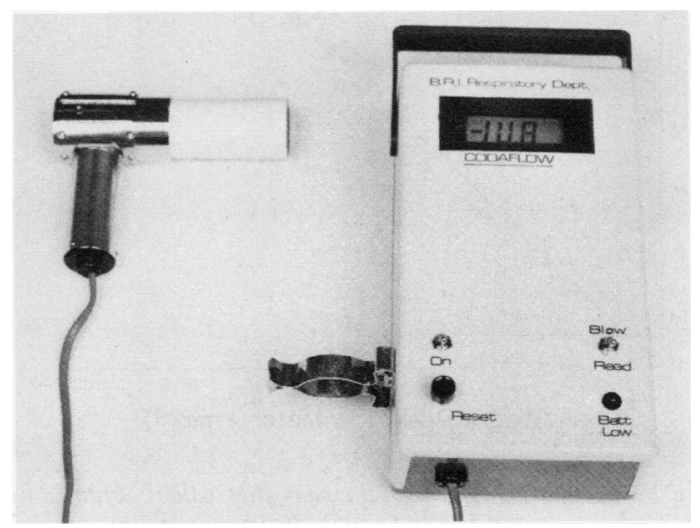

Fig 1 The Codaflow. 
relayed to the electronics housed in the instrument case. The instrument selects and displays the maximum flow rate sustained for more than 10 milliseconds. We preset the range of each instrument so that the top of the scale represented a steady flow of $7201 \mathrm{~min}^{-1}$ (this is adjustable).

The display can be coded. The code is obtained by (a) using symbols to represent single numerals, tens, and hundreds-for example, 1, 2, 3, 5, 6, 8, 9, ., -, A, $\mathrm{E}, \mathrm{U}$, and $(b)$ interchanging the position of the ones, tens, and hundreds. We divided the scale into one hundred steps; by the use of more digits a greater number of steps are available. The only information a user needs is the code for zero: -1 U.8. There are three switches on the instrument case (fig 1) - an onoff switch, a reset button for returning the display to zero, and a blow-read switch. During the peak flow manoeuvre this switch is on "blow" and the display reads zero ( $-1 \mathrm{U} .8)$. After the manoeuvre the switch is turned to "read" and the peak flow is displayed and held.

The Codaflow runs on four HP7 batteries or their equivalent, which have a life of several months in normal use.

\section{PERFORMANCE}

We have compared the performance of the Codaflow with the Wright peak flow meter, using steady flow

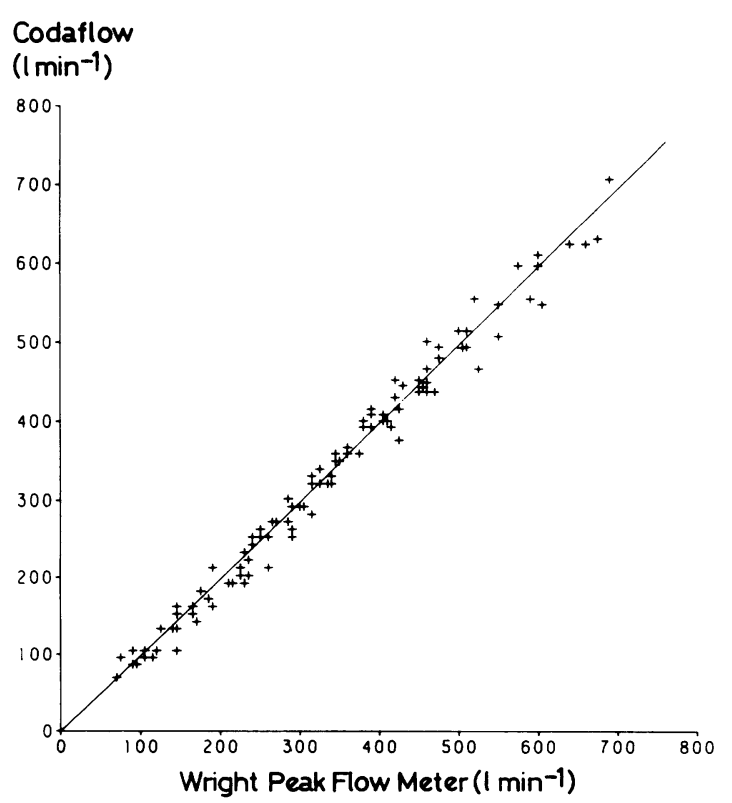

Fig 2 Comparison between the peak flow values obtained by the Codaflow and the Wright peak flow meter in 100 outpatients. The line shown is the line of identity. rates and artificial peak flows. ${ }^{1}$ With both techniques the Codaflow had a linear response to within $1 \% \frac{\overrightarrow{0}}{0}$ whereas the Wright PFM was less linear, as described previously. ${ }^{2-4}$ In a clinical comparison in 100 outpatients close agreement between the readings from the two peak flow meters was obtained ${ }^{1}$ (fig 2).

Performance is dependent on the characteristics of the turbine and does not change with use, or between $\vec{\circ}$ instruments provided that the turbine manufacture is $\overrightarrow{\vec{H}}$ identical. Eight instruments have now been tested. Variation between instruments is less than $2 \%$, both $\overrightarrow{\vec{\gamma}}$ for steady state and for artificial peak flows. After extensive use the Codaflow has proved to be reliable with no change in performance characteristics. So far we have used only one variant of the code, which no user has broken in a total of more than 1500 user days.

\section{Subjects and methods}

We studied 12 subjects with unstable asthma, 10 male and two female, aged 19 to 59 years. The duration of their asthma varied from 13 to 40 years. All medica- $\vec{\oplus}$ tion remained unchanged for the period of the study, $\beta_{2}$ adrenergic inhalers being used as required in most cases. Each patient recorded a subjective assessment of asthma followed by three consecutive values of PEF at least three times a day for four weeks, using a coded peak flow meter for two weeks and an uncoded meter for two weeks in randomised order. Each meter was calibrated before use. Self assessment of the severity of asthma was made by marking the answer to the question "How is your asthma?" on a $10 \mathrm{~cm}$ visual analogue scale labelled "no asthma" at the left end and the "most severe" ever experienced at the right. The subjects answered this question in relation to their asthma at the present moment.

The results were analysed by plotting asthma score on the visual analogue scale against the best of the three peak flow readings recorded immediately afterwards. Regression lines were obtained for observations using the coded and uncoded meters respectively and compared by analysis of variance. The methods used were as described by Armitage ${ }^{5}$ for comparing differences in slopes, and where slopes are $\tilde{N}$ not significantly different for comparing the position $N$ of the regression lines (analysis of covariance). When the residual variances about the regressions were $\omega$ significantly different we used the $\mathrm{G}$ statistic. ${ }^{5}$ Correlations of visual analogue asthma score with $\mathrm{PEF}$ were compared by means of the $\mathrm{Z}$ statistic. ${ }^{6}$

\section{Results}

All 12 patients satisfactorily completed the diary $\frac{\Omega}{\mathbb{D}}$ cards for the four weeks. Regression lines for visual 


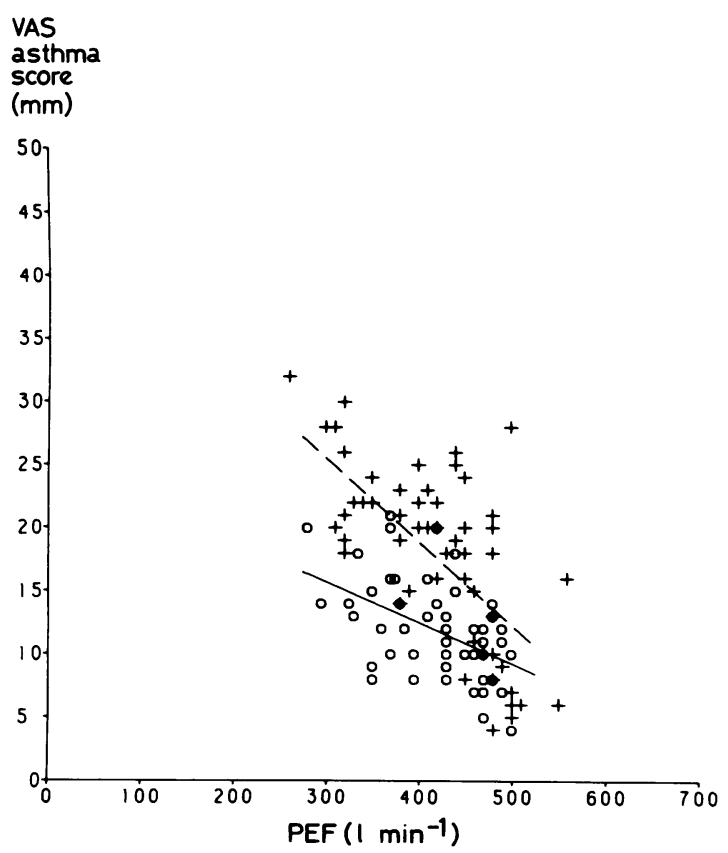

Fig 3 The relationship between visual analogue scale (VAS) asthma score and peak flow (PEF) in one patient. Uncoded PEF data ( + ) and regression line (----). Coded PEF data ( $\bigcirc)$ and regression line (-

analogue scale asthma scores against PEF were obtained from 10 patients, allowing comparison of correlation slopes, and relative positions. An example is shown in figure 3 . In two patients who showed an obvious threshold for symptoms of asthma this analysis was not possible.

For all 10 subjects the correlation between visual analogue asthma score and PEF was closer when the uncoded meter was used; in five subjects the difference reached significance at the $5 \%$ level. In no subject was the correlation closer when PEF was coded (table 1). In all 10 patients whose data were suitable for analysis the correlation between visual analogue asthma score and PEF was significant at the $1 \%$ level when they were using the uncoded meter, ranging from -0.46 to -0.87 . For the coded data correlations ranged from -0.07 to -0.74 , achieving significance at the $1 \%$ level in seven patients. There was no difference between those using the uncoded meter first and those using the coded meter first.

The slope of the regression line is an index of awareness of change in severity of asthma as measured by PEF. The slope was significantly steeper at the $5 \%$ level (more negative) during use of the uncoded meter in five subjects (table 1). In one subject the slope was significantly steeper during use of the coded meter. Mean PEF values and mean visual analogue asthma scores (table 2) were not significantly different between the coded and uncoded periods. In the five subjects whose slopes changed significantly the mean PEF values were $3511 \mathrm{~min}^{-1}$ for the uncoded period and $3271 \mathrm{~min}^{-1}$ for the coded period, again not significantly different; but the visual analogue asthma scores were $43.0 \mathrm{~mm}$ for the uncoded period and $25.1 \mathrm{~mm}$ for the coded period.

A difference in position of the regression lines for the coded and uncoded meters also indicates a change in subjective assessment-that is, with an upward shift in position there is an increase in the subjective scoring of asthma for a given PEF. The regression line was significantly higher in position $(p<0.05)$ during use of the uncoded meter in five subjects. In one subject there was a significant upward shift in position using the coded meter.

The subjects whose awareness of change in severity of asthma was substantially altered by knowledge of

Table 1 Data for the regression lines describing the relationship between visual analogue scale asthma score and peak flow $(P E F)$ for the uncoded $(U)$ and coded $(C)$ periods

\begin{tabular}{|c|c|c|c|c|c|c|c|c|c|}
\hline \multirow{2}{*}{$\begin{array}{l}\text { Subject } \\
\text { No }\end{array}$} & \multirow[b]{2}{*}{ Sex } & \multirow{2}{*}{$\begin{array}{l}\text { Age } \\
(y)\end{array}$} & \multicolumn{2}{|c|}{ Correlation $(-r)$} & \multirow{2}{*}{$\begin{array}{l}\text { Significance } \\
\text { of difference } \\
\text { in } r(p \text { value })\end{array}$} & \multicolumn{2}{|c|}{ Slope $(-b)$} & \multirow{2}{*}{$\begin{array}{l}\text { Significance } \\
\text { of difference } \\
\text { in } b(p \text { value })\end{array}$} & \multirow{2}{*}{$\begin{array}{l}\text { Significant } \\
\text { shift in } \\
\text { positiont }\end{array}$} \\
\hline & & & $U$ & $C$ & & $U$ & C & & \\
\hline 1 & $\mathbf{M}$ & 32 & 0.87 & 0.44 & $<0.1$ & 0.21 & 0.06 & $<0.001$ & - \\
\hline 2 & $\mathbf{M}$ & 33 & 0.66 & 0.46 & NS & 0.067 & 0.03 & $<0.01$ & $\uparrow$ \\
\hline 3 & $\mathbf{M}$ & 19 & 0.61 & 0.19 & $<0.05$ & 0.04 & 0.01 & 0.02 & - \\
\hline $4^{*}$ & $\mathbf{M}$ & 32 & 0.62 & 0.53 & NS & 0.09 & 0.11 & NS & $\uparrow$ \\
\hline $5^{*}$ & $\mathbf{M}$ & 41 & 0.76 & 0.74 & NS & 0.10 & 0.16 & $<0.05$ & \\
\hline 6 & $\mathbf{M}$ & 37 & 0.78 & 0.35 & $<0.001$ & 0.26 & 0.10 & $<0.001$ & $\uparrow$ \\
\hline $7^{*}$ & $\mathbf{F}$ & 42 & 0.82 & 0.07 & $<0.001$ & 0.05 & 0.01 & $<0.001$ & 1 \\
\hline $8^{*}$ & $\mathbf{M}$ & 37 & 0.64 & 0.31 & $<0.001$ & 0.09 & 0.06 & NS & $\uparrow$ \\
\hline 9* & $\mathbf{M}$ & 59 & 0.46 & 0.45 & NS & 0.08 & 0.07 & NS & $\uparrow$ \\
\hline $10^{*}$ & $M$ & 29 & 0.60 & 0.54 & NS & 0.08 & $0 \cdot 10$ & NS & 1 \\
\hline $\begin{array}{l}11 \\
12\end{array}$ & $\begin{array}{l}\mathbf{M} \\
\mathbf{F}\end{array}$ & $\left.\begin{array}{l}45 \\
40\end{array}\right\}$ & \multicolumn{5}{|c|}{ Analysis by linear regression not possible } & & \\
\hline
\end{tabular}

* Coded PEF before uncoded PEF,

$+\mathrm{p}<0.05$.

$+\uparrow$-Upward shift in position when PEF uncoded; $\downarrow$ - downward shift in position when PEF uncoded. 
Table 2 Mean visual analogue scale (VAS) asthma scores, peak flow (PEF), and diurnal variation for the uncoded (U) and coded $(C)$ periods

\begin{tabular}{|c|c|c|c|c|c|c|}
\hline \multirow[b]{2}{*}{ Subject No } & \multicolumn{2}{|c|}{ Mean VAS score } & \multicolumn{2}{|c|}{ Mean PEF } & \multicolumn{2}{|c|}{ Mean diurnal variation in $P E F(\%)$} \\
\hline & $U$ & $C$ & $U$ & $C$ & $U$ & $C$ \\
\hline $\begin{array}{r}1 \\
2 \\
3 \\
4 \\
5 \\
6 \\
7 \\
8 \\
9 \\
10\end{array}$ & $\begin{array}{r}44 \cdot 1 \\
17.5 \\
5.7 \\
24.9 \\
9.6 \\
42.4 \\
5.4 \\
46.7 \\
22.9 \\
7.6\end{array}$ & $\begin{array}{r}59.3 \\
12.0 \\
7.0 \\
23.3 \\
10.7 \\
30.6 \\
7.1 \\
45.2 \\
17.0 \\
7.4\end{array}$ & $\begin{array}{l}387 \\
421 \\
477 \\
274 \\
252 \\
163 \\
337 \\
429 \\
271 \\
335\end{array}$ & $\begin{array}{l}269 \\
417 \\
404 \\
232 \\
218 \\
203 \\
315 \\
377 \\
306 \\
364\end{array}$ & $\begin{array}{l}19 \\
24 \\
27 \\
21 \\
31 \\
39 \\
20 \\
14 \\
29 \\
34\end{array}$ & $\begin{array}{l}18 \\
25 \\
27 \\
18 \\
32 \\
22 \\
19 \\
14 \\
23 \\
26\end{array}$ \\
\hline
\end{tabular}

PEF were not distinguishable by age, sex, duration of asthma, severity of asthma, diurnal variation in PEF, or order of peak flow meters.

Six subjects have since repeated the coded part of the study, at an interval of three to six months after the first study, with no use of a peak flow meter in the interim. They were selected because there has been no change in their asthma treatment. The same methods were used, with three PEF recordings after each scoring of asthma. In none was there a significant change in slope.

\section{Discussion}

The use of turbine flow transducers in respiratory function testing has been reported previously. ${ }^{7}$ We compared the Codaflow with the Wright peak flow meter because the latter and its derivative (the mini Wright peak flow meter) are in common use. The calibration of peak flow meters is controversial. $^{2-489}$ We calibrated the meters used in the study against a Fleisch pneumotachograph. ${ }^{1}$ The greater linearity of the Codaflow may be due in part to its lower resistance. The correlation between the Codaflow and Wright peak flow meter in 100 outpatients was as good as that quoted for the mini Wright peak flow meter. ${ }^{9}$ The code has yet to be broken by any user. If necessary it can be changed. The method of coding is suitable for other instruments using a similar form of display.

This study shows that knowledge of recent values of peak flow influences self assessment of the severity of bronchial asthma. Of the 10 patients whose data were suitable for analysis, five showed a significantly higher correlation between visual analogue scale asthma score and PEF when PEF was uncoded, and in no patient was it lower. Five were significantly less aware of the changes in severity of their asthma and scored their asthma as less severe when the PEF was coded, with only one patient seemingly more aware of his asthma when PEF was coded.
A closer correlation during use of the uncoded meter could occur if the measured peak flow was nearer the true potential maximum peak flow. Comparison of the coded and uncoded sets of three consecutive PEF recordings for each subject, however, showed no difference in the variability of the three PEF records and, in particular, no difference in the frequency with which the maximum PEF occurred first, second, or third in each group of triplicate measurements. Since in addition the mean PEF values were not significantly different, the data do not support this possibility.

A change in slope between coded and uncoded periods could occur because of deterioration in asthma with a fall in mean PEF and increased diurnal variation of PEF. But there was no difference in mean PEF or in diurnal variation between the coded and uncoded periods either for all the subjects or for those subjects whose slopes were significantly altered (table 2 ). In only one subject was an increase in slope associated with a fall in PEF and an increase in diurnal variation in PEF.

For the five subjects whose slopes were significantly different in the coded period, the mean PEF was not different from that of the uncoded period but the mean visual analogue scale asthma score was lower. The values for residual variance about each 을 regression, (which, unlike correlation, is independent $D$ of slope) showed no evidence that knowledge of trends in PEF influences the scatter around the $N$ relationship between visual analogue score and peak flow. Moreover, in five of the 10 subjects there was an upward shift in position of the regression line when $\mathrm{\omega}$ PEF was uncoded - that is, visual analogue scores were higher for a given PEF. We therefore, suggest as 0 a likely explanation of the findings that some subjects use the visual analogue scale differently when they?

know the trends of their PEF.
The subjects were asked always to mark their visual analogue scale before recording PEF. We cannot be $\bigcirc$ certain that the patients did not "cheat" by recording $\triangle$ 
PEF first, but on being questioned after the study only one patient admitted to doing this occasionally. It has been shown that patients with asthma accustomed to using a peak flow meter are quite good at guessing their PEF, ${ }^{10}$ but only two of our group had previous experience of home PEF records. Possibly this knack can be learned within two weeks, but the patients who used an uncoded meter first were not distinguishable from the others. Conscious or subconscious study of trends in PEF could mean that unusually good or bad early morning values of PEF affect the perception of symptoms for the rest of that day. Such an effect would be more pronounced in those studies in which symptoms are recorded only once a day.

It has been suggested that in asthmatic outpatients the correlation between symptoms and PEF is poor, ${ }^{11}$ but in some selected individuals it can be quite good. ${ }^{12}$ We found this correlation to be surprisingly good in our patients when PEF was not coded and fairly close in six patients even when PEF was coded. We have shown here that the good correlation is in part caused by suggestion, but the difference between our subjects and previous groups may be explained by differences in the technique of self assessment. In a pilot study we found that one question ("How is your asthma"), answered on a $10 \mathrm{~cm}$ visual analogue scale, gave better discrimination in self assessment than a fixed set of symptoms scored $0-4$ (unpublished observations). This is probably because the visual analogue scale is more sensitive than an ordinate scale and widely varying symptoms are used by patients to assess their asthma.

This study suggests that if patients with airflow obstruction are to be asked to make comparisons about the clinical efficacy of different treatments, however well controlled the study, the objective measurements of airflow obstruction have to be concealed from them. Relationships between symptoms and lung function on diary card records must be interpreted with caution if the lung function results are available to the patient.

On the other hand, a proportion of patients with asthma are "poor perceivers," remaining unaware of considerable deterioration in their airway calibre. It has been suggested that such individuals are at risk from sudden deterioration. ${ }^{13}{ }^{14} \mathrm{~A}$ therapeutic implication of this study is to confirm that home monitoring of PEF in relation to symptoms heightens awareness of asthma, particularly in those with poor perception of their asthma. Further studies would be needed to show how long the heightened awareness lasts.

With coded readings, falsification is identifiable because all three attempts are recorded and closely related numbers cannot be invented by the subject. Three identical attempts are rarely achieved by subjects with asthma. Sub maximal efforts can be identified by widely disparate low readings. In studies of asthma investigating extrinsic factors, occupational or otherwise, particularly where compensation or litigation is concerned, patients may consicously or subconsciously falsify their PEF records. Coding the PEF would increase the reliability of these records.

Using this new coded peak flow meter we have shown that knowledge of home peak flow recording influences subjective assessment of asthma and may improve perception of airflow obstruction. When objective and subjective changes in asthma are to be studied at the same time the results of measurements of lung function must not be available to the patient.

This work was carried out during the tenure of the Carey Coombs research fellowship awarded to CMBH by the special trustees of the Bristol Royal Infirmary. We thank Audrey Sawyer for the typing.

\section{References}

I Richardson RB, Higgs CMB, Lea DA, Lewis GTR, Laszlo G. An electronic peak flow meter with optional coded display. Clin Phys Physiol Meas 1984;5:201-6.

2 Fisher J, Shaw A. Calibration of some Wright peak flow meters. Br J Anaesth 1980;52:461-4.

3 Morrill CG, Dickey DW, Weiser PC, Kinsman RA, Chai $H$, Spectors SL. Calibration and stability of standard and mini Wright peak flow meters. Ann Allergy 1981;46:70-3.

4 Shephard RJ. Some observations on peak expiratory flows. Thorax 1962;17:39-48.

5 Armitage P. Statistical methods in medical research. Oxford: Blackwell Scientific Publications, 1971: 279-95.

6 Snedecor GW, Cochran WG. Statistical methods. 6th ed. Iowa State University, 1967:185.

7 Chowienczyk PJ, Lawson CP. Pocket-sized device for measuring forced expiratory volume in one second and forced vital capacity. Br Med J 1982;285:15-7.

8 Wright BM. Calibration of peak flow meters [letter]. $\mathrm{Br} J$ Anaesth 1981;53:777.

9 Oldham HG, Bevan MM, McDermott M. Comparison of the new miniature Wright peak flow meter with the standard Wright peak flow meter. Thorax 1979;34: 807-9.

10 Shim CS, Williams MH jun. Evaluation of the severity of asthma: patients versus physicians. $A m J$ Med 1980;68:11-3.

11 Clark TJH. Clinical aspects of diffuse airways obstruction. In: Lane DJ, ed. Respiratory disease. London: Heinemann, 1976:244.

12 Rubinfeld AR, Pain MCF. Relationship between bronchial reactivity, airway caliber, and severity of asthma. Am Rev Respir Dis 1977;115:381-7.

13 Anonymous. Saving asthmatics. Br Med J 1979;i:520-1.

14 Ormerod LP, Stableforth DE. Asthma mortality in Birmingham 1975-7: 53 deaths. $\mathrm{Br} \mathrm{Med} J$ 1980;280: 687-90. 